\title{
Design of a hydraulically controlled conveyor belt clamp for heavy-duty drift belt installation in underground applications: a case study
}

\section{G. Wheatley}

To cite this article: G. Wheatley (2020) Design of a hydraulically controlled conveyor belt clamp for heavy-duty drift belt installation in underground applications: a case study, Journal of Structural Integrity and Maintenance, 5:3, 171-182, DOI: 10.1080/24705314.2020.1765267

To link to this article: https://doi.org/10.1080/24705314.2020.1765267

\section{曲 Published online: 29 Jul 2020.}

Submit your article to this journal ๘

Q View related articles $\sqsubset$

View Crossmark data ¿ 


\title{
Design of a hydraulically controlled conveyor belt clamp for heavy-duty drift belt installation in underground applications: a case study
}

\author{
G. Wheatley \\ College of Science \& Engineering, James Cook University, Townsville, Australia
}

\begin{abstract}
The following paper provides a summary of the design and operating parameters for the Dynamic Belt Clamp. The Dynamic Clamp is hydraulically controlled to apply braking force on a belt via reference from an operator input. Belt braking force is proportional to hydraulic pressure applied. The clamp is not designed to be "fail safe" with the clamp opening when hydraulic system pressure is lost. Hand calculations were used along with finite element analysis to determine the structural stresses induced by the combined clamping force and belt tension. A 20 Metric Tonne belt tension capacity (196.1 kN lateral load) has been nominated for design purposes. A belt thickness of $50 \mathrm{~mm}$ has been assumed as a worst case for design purposes. In addition, a dynamic coefficient of friction of 0.2 has been assumed for the contact surfaces between the belt and the clamping beam surfaces. Australian Standard AS1418.1 - Cranes, Hoists and Winches General and AS3990 Mechanical Equipment - Steelwork have been utilized for determining the suitability of the design. The design meets the requirements of the standards for the proposed clamping loads and belt tensions. The combined stresses do not exceed allowable stress or displacement recommendations.
\end{abstract}

\section{KEYWORDS}

Conveyor; belt; installation; brake; dynamic; clamp

\section{Introduction}

Conveyor systems are extremely common across many industries (Malek et al., 2015) and are especially common within the mining industry in Australia. Belt conveyors are known to be easy and relatively cheap to maintain. They have high loading and unloading capacity. Dense material transport is cheap and efficient over long distances. The variability of the bulk material can also be accommodated (Daniyan et al., 2014).

The wear and tear of the conveyor belts is affected by many factors including the material, design of the loading bin feeding onto the conveyor belt, belt type, cover rubber, conveyor length, idler spacing, belt speed, scrapers, operational procedures, environmental variations and the quality of the service on the conveyor (Blazej \& Jurdziak, 2017).

The installation of new belt is an expensive and potentially dangerous series of operations that require a wide range of equipment and experienced technicians. Winders, flake piles and roller stands (Wheatley, 2018), turning frames (Wheatley, 2018), let off stands, etc., are all highly engineered and purpose built pieces of equipment.

The belt replacement process includes the following general stages. Firstly, a detailed and approved plan for belt replacement must be produced. This includes a full hazard and risk reduction plan. It also must include a review process so that downtime is kept to a minimum and quality standards are adhered to. It is only when this plan is approved that work permits are issued. The necessary equipment, tools, and materials are usually arranged by both the mine and the contracting company as often the larger equipment or splice kits are not owned by the mine. The belt is examined so that any repairs that have caused belt damaged can be repaired so that the new belt is not damaged. Needless to say, the bulk material must be removed from the conveyor system. The conveyor is locked out as any movement is not permitted.
Further, the full area is taped off so a safe work area is ensured. The belt is then de-tensioned and equipment put in place. It is very important that the equipment is placed in such a fashion such that the belt is not unnecessarily bent or twisted. Any structure or idlers that need to be removed in order to facilitate belt replacement is then removed. The old belt is then clamped and cut. The new belt is temporarily spliced to the old belt and the old belt can be removed and wound up on reels while the new belt is drawn onto the system (PMBROD367B, 2012).

It is at this time that the belt clamp on which this paper is concerned is used. It there is any substantial change in elevation of the conveyor system then belt clamps must be used to prevent runaway. Both a braking clamp or clamps and an emergency clamp or clamps must be used. The hydraulic clamp uses hydraulic pressure to clamp on the belt to provide adjustable braking while the belt travels down any slope. The emergency clamp uses springs to clamp down and hydraulic pressure to open. As such, if there is a loss of power, the emergency clamps automatically operate and stop the belt from a runaway situation.

The old belt will be wound onto reels and cut as the reels fill. The new belt is wound onto the system and permanently spliced as each reel is emptied. This process may be slightly different if the new belt has already been flaked out and permanently spliced with only the final splice to be completed (Wheatley, 2018). After the old belt is removed, the new belt can then have the final splice completed and commissioning can take place which includes ensuring that the belt tracks properly empty and when full of bulk material. Finally, the area can be fully cleaned and removed of equipment such that normal operations can be reinstated (PMBROD367B, 2012).

The design process for any piece of industrial equipment broadly must consider the essence of any project activity, the 
Table 1. Summary of permissible stresses.

\begin{tabular}{lc}
\hline Permissible axial tensile stress & $216 \mathrm{MPa}$ \\
Permissible stress due to bending & $238 \mathrm{MPa}$ \\
Permissible compressive stress, bending about x-axis & $238 \mathrm{MPa}$ \\
Permissible compressive stress, bending about $y$-axis & $238 \mathrm{MPa}$ \\
Permissible average compressive stress & $180 \mathrm{MPa}$ \\
Permissible maximum shear stress & $162 \mathrm{MPa}$ \\
Permissible average shear stress & $133.2 \mathrm{MPa}$ \\
\hline
\end{tabular}

broad structure of the proposed equipment, and the history of such activity and equipment. In order to accomplish these three broad objectives, a number of tasks must be addressed. Firstly, one must identify. The essential content of the design must be determined when considering the subject, object, relationship between them and the activity that is wished to be completed. Secondly, the structure of the design must be considered from the activity methodological concept basis. Thirdly, the historical designs should be considered. Fourthly, the relationship between designer, user, and the design must be considered. Fifthly, any recent technological or other innovations that might impact the design should be considered. Finally, other considerations such as training that may be required, financial support, state support, and aesthetics must be considered (Popov, 2019).
"The jointing of belts can be hazardous if suitable equipment is not used. For small conveyors, hand operated tirfors or pulllifts with properly rated chains and belt clamps may be used safely. With larger conveyors, this method may not be adequate and drives have often been misused to throw slack belt. This is fraught with danger since the forces developed by the drive cannot be properly controlled and may exceed the safe working loads of the clamps, chains, etc. Where hand-operated equipment is not sufficient, purpose-designed powered equipment is necessary. The drive should always be isolated before jointing work commences and remain so until the work has been completed and the clamps removed." (https://www.hse.gov.uk/ pUbns/priced/belt-conveyors-mines.pdf).

The Dynamic clamping system is designed specifically to assist in installation of heavy-weight conveyor belt onto incline or decline conveyor systems. The Dynamic clamp system incorporates two heavy clamp beams along with associated hardware and a hydraulic control system. The two clamp beams are forced together by two large hydraulic cylinders to apply a clamping force on the belt which in turn creates a controllable braking force to effectively "slip" the belt through the clamp. The amount of braking force available is proportional to the friction coefficient between the steel clamp faces and the rubber belt. Mediums such as dirt,

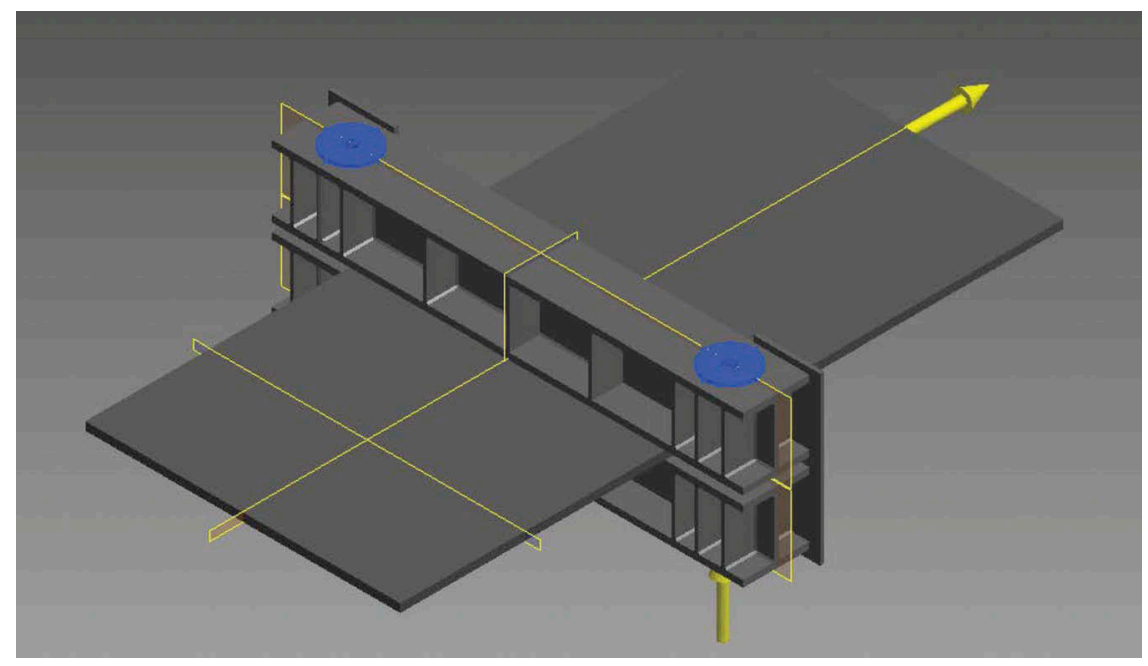

Figure 1. Fixed area on the top beam where mounting will occur.

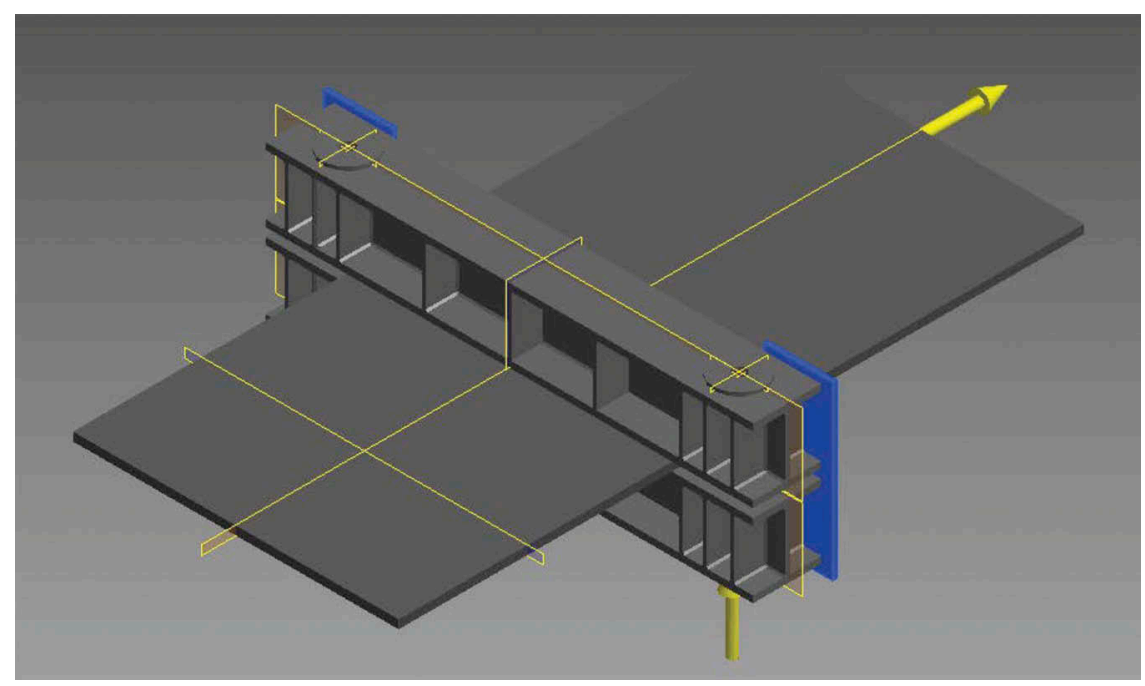

Figure 2. Vertical support areas that offer a frictionless surface for the top and bottom beams to move against. 


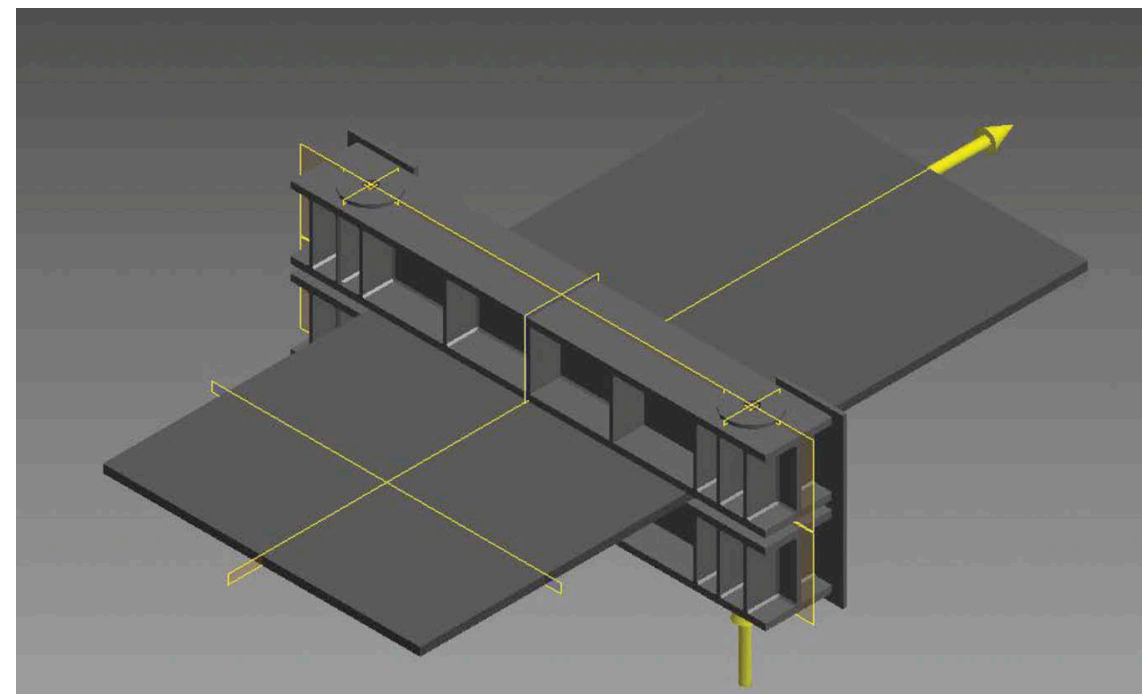

Figure 3. Evenly applied load applied to belt end.

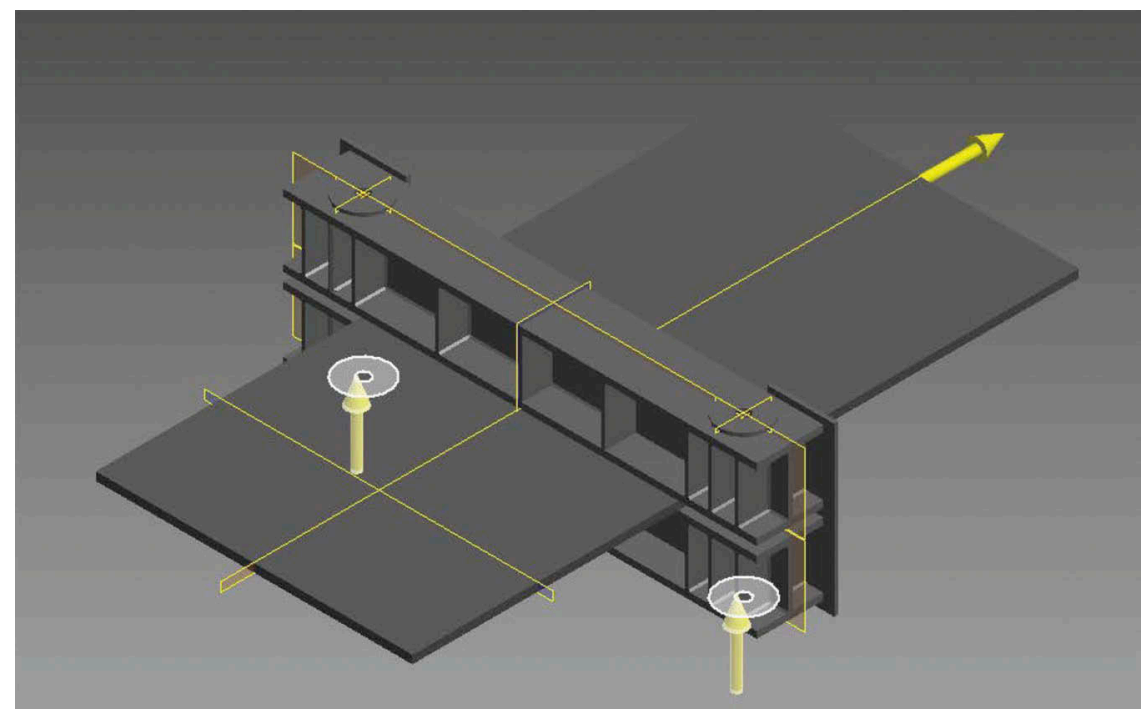

Figure 4. Loads applied to clamp where hydraulic force will be applied.

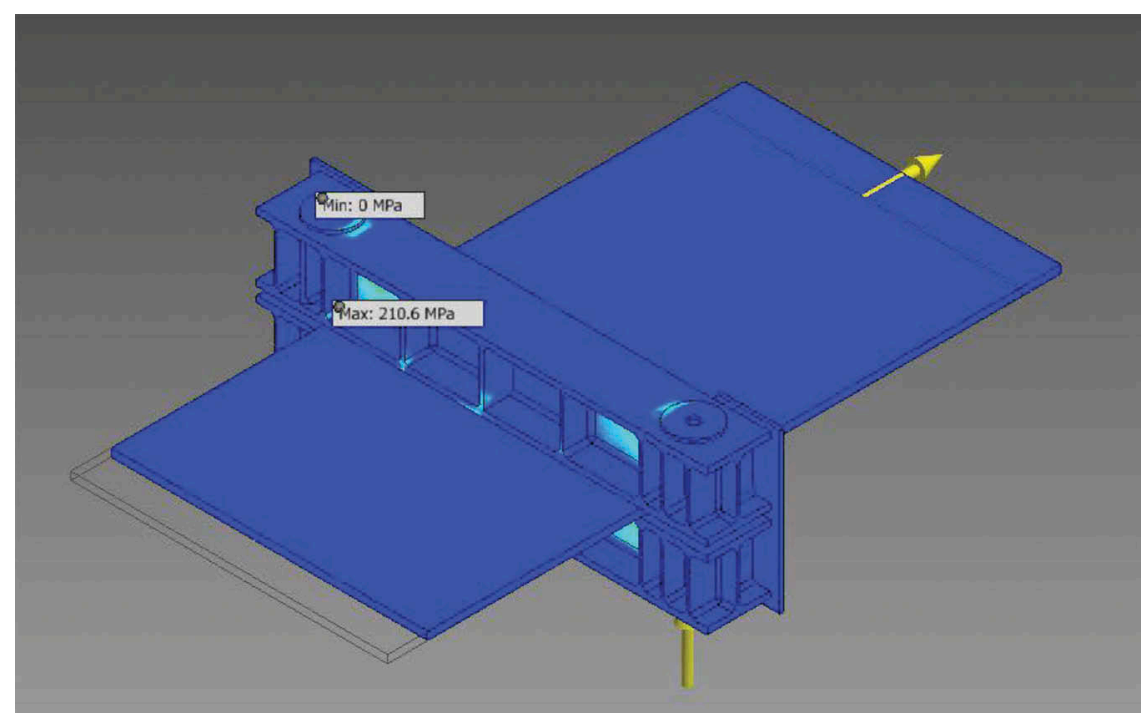

Figure 5. Maximum stress. 


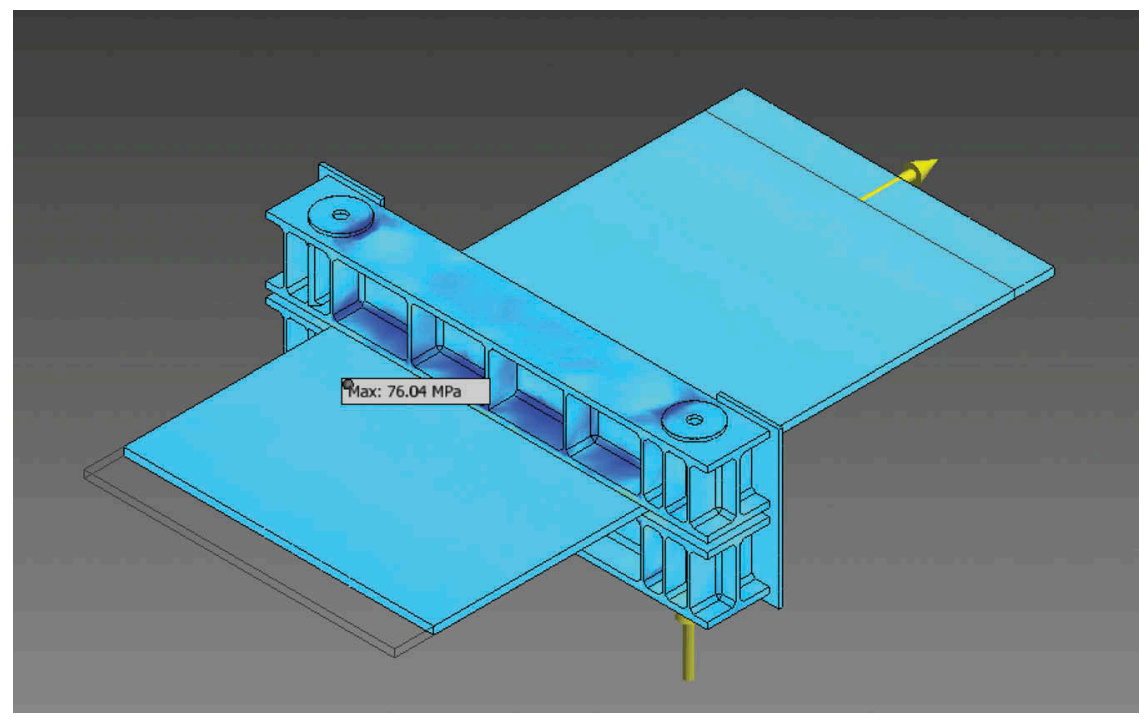

Figure 6. Maximum ZZ stress with NO Safety factors applied.

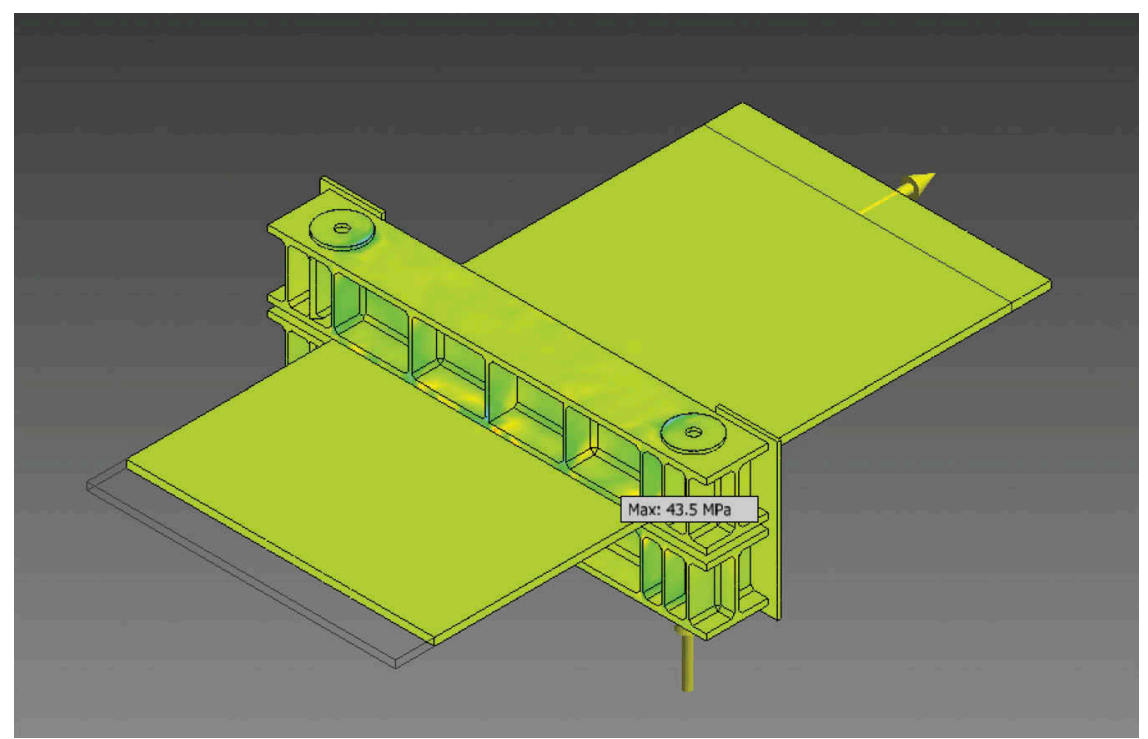

Figure 7. Maximum YY stress with NO safety factors applied.

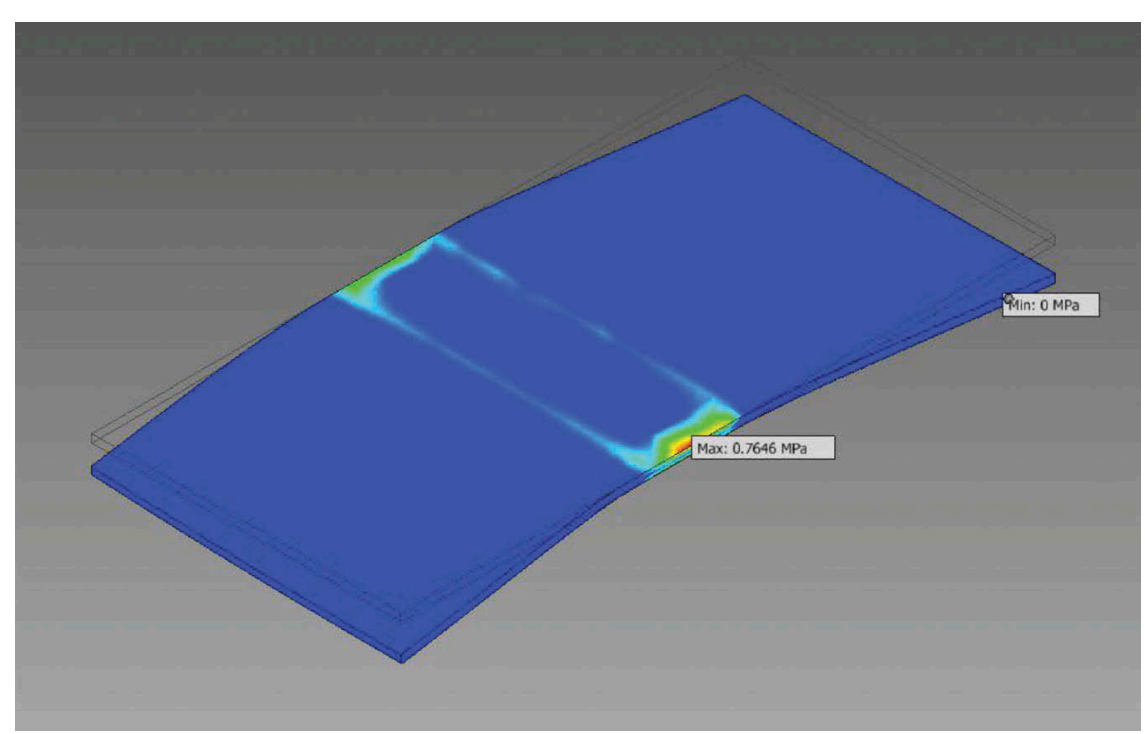

Figure 8. Stress on belt. 


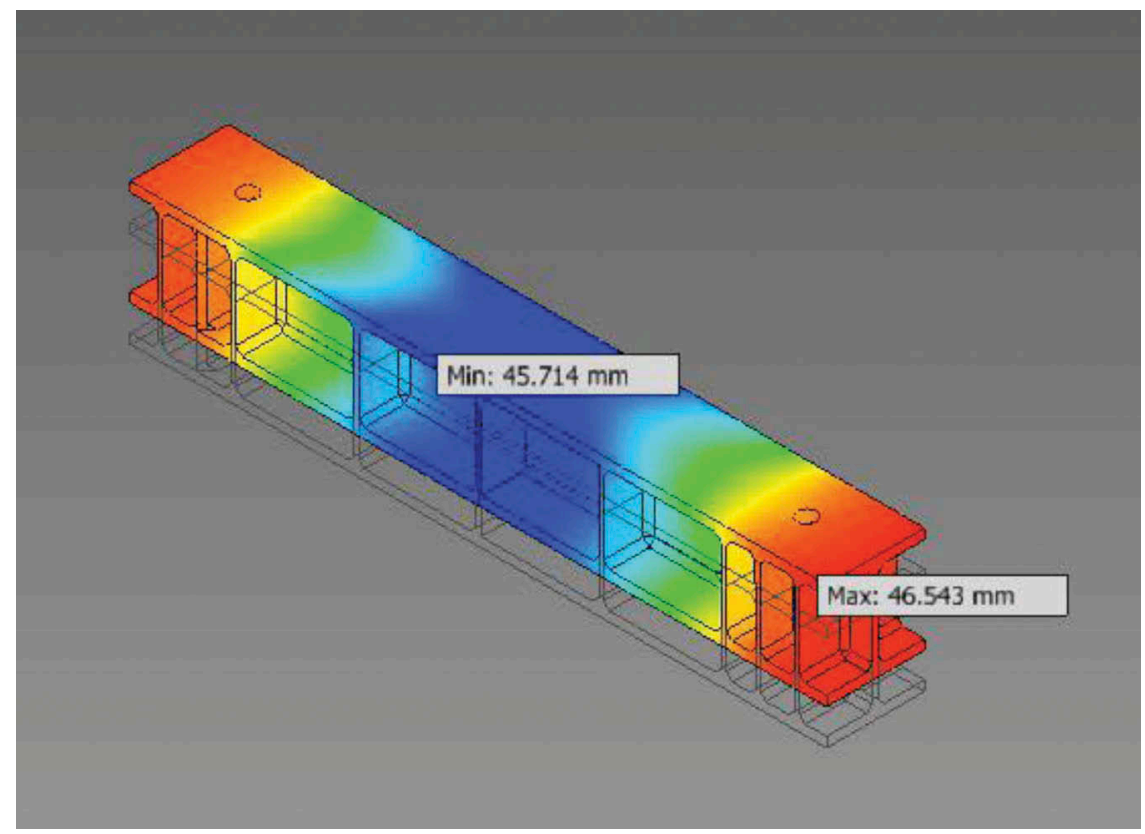

Figure 9. Top beam $Y$ deflection.

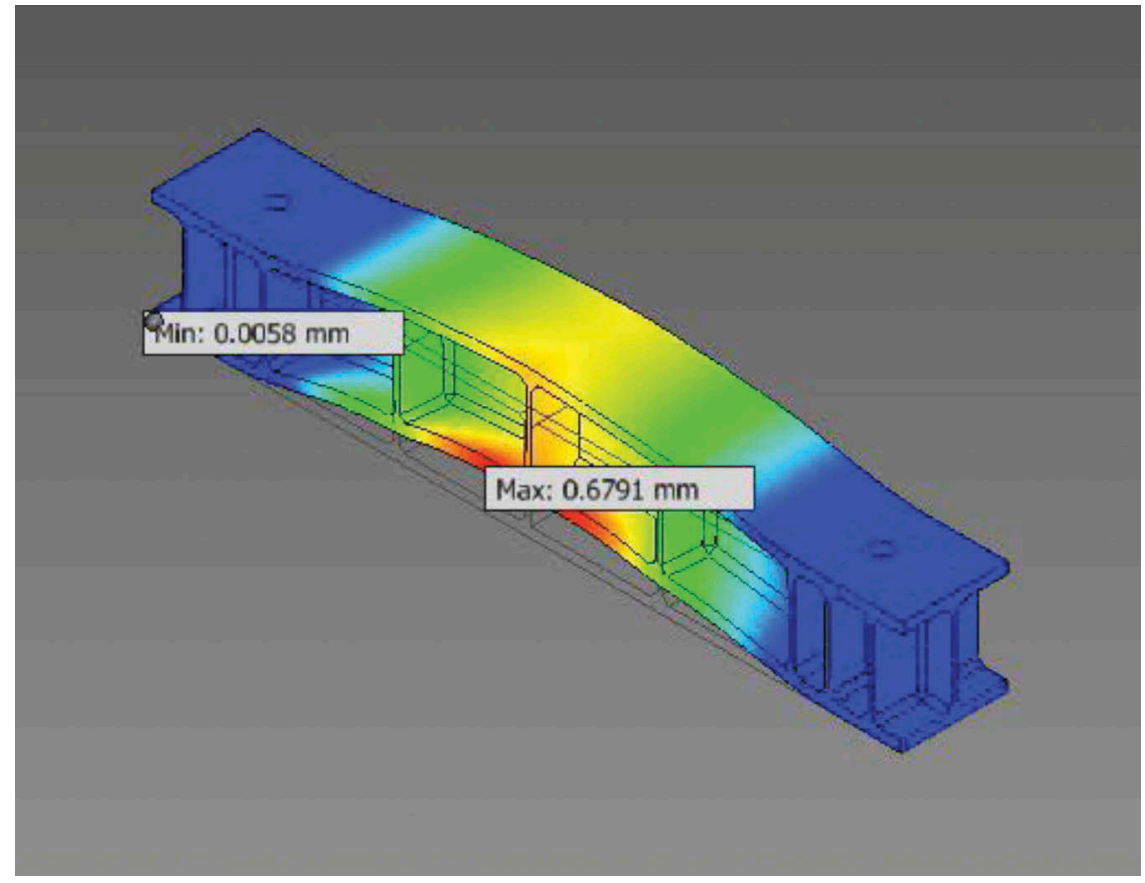

Figure 10. Top beam Z deflection.

moisture, waxes, oils, and others will affect the amount of braking force the clamp will be able to effectively apply. Considerations have been made and checks applied, respectively, to avoid the potential of damage to the belt from excessive clamping forces and associated friction generated heat build-up.

The following design assumptions have been made. The Dynamic Belt Clamp will be used with belt of equal or less than $50 \mathrm{~mm}$ in thickness. The Dynamic Belt Clamp will be used for belt widths between 1000 and $2000 \mathrm{~mm}$. Maximum clamping pressure is not to exceed $2.8 \mathrm{MPa}$ on the belt. The clamp will need to be capable of restraining a lateral load of 20 Metric Tonnes force. A factor of safety of 2 has been applied. The resulting design lateral load used is 40 Metric Tonnes (392.3 kN). A dynamic coefficient of friction of 0.2 has been assumed for the contact surfaces between the belt and the clamping beam surfaces. The maximum clamping force has been taken to be 87 Tonnes $(853.2 \mathrm{kN})$. A safety factor of 1.5 has been used. The design load is therefore 130.5 Tonnes $(1279.8 \mathrm{kN})$. The clamp is assumed to be abutted against vertical supports. This requirement has been included in the operating instructions for the equipment. As a result, no lateral loading is assumed on the threaded bars. The clamp is assumed to be mounted with the hydraulic cylinders oriented on the top of the clamp. The hydraulic pistons used are unidirectional operating to close the clamp only. It 


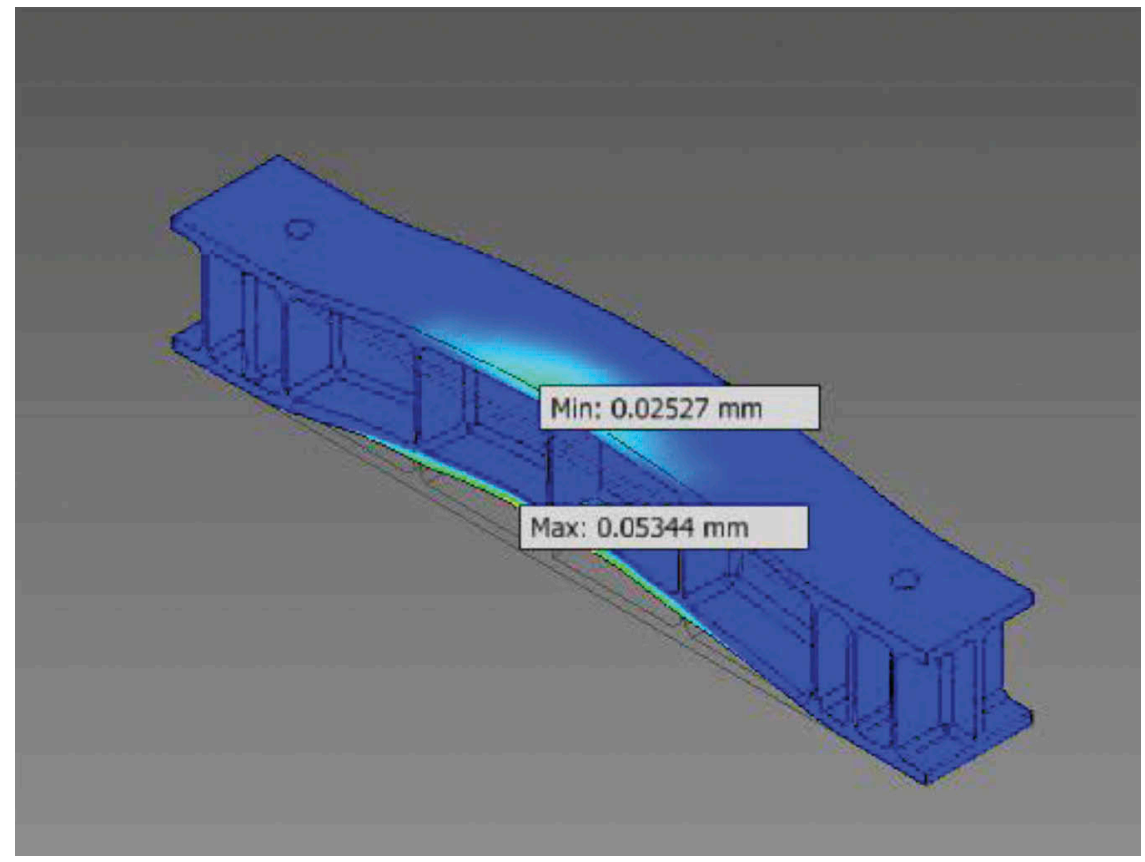

Figure 11. Bottom beam Y deflection.

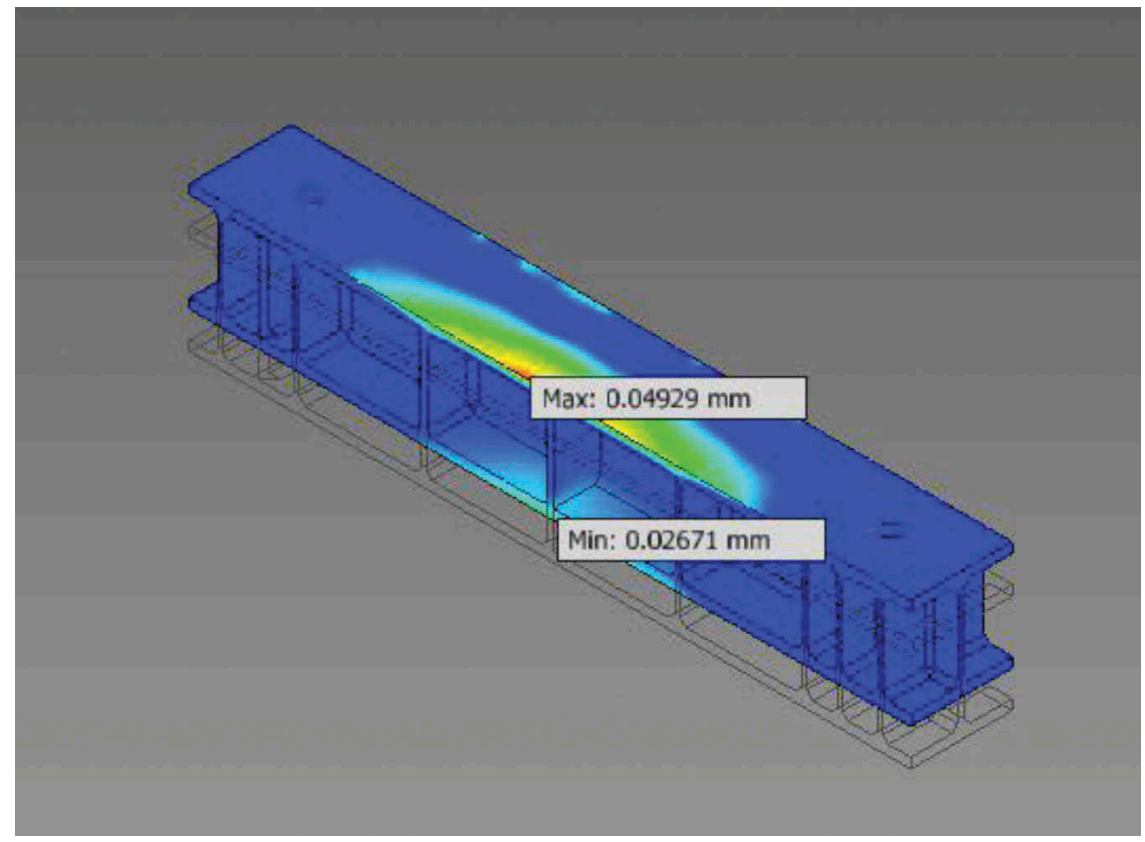

Figure 12. Bottom beam $Z$ deflection.

is assumed that the belt has been oriented such that the centerline of the belt is collinear with the centerline of the clamp. As a result, no lateral loading along the length of the clamp is assumed.

\section{Hand calculations}

\section{Design to AS1418.1 - cranes, hoists, and winches general}

Australian Standard AS1418.1 - Cranes, Hoists, and Winches General specifies that the vertical deflection of the span (i.e. parallel to the load direction) must be less than $1 / 500$ of the span $(<0.2 \%)$ or $60 \mathrm{~mm}$, whichever is the lessor, when no dynamic factor is taken into account in the calculation. The standard also stipulates that the dynamic factor shall be between 1.5 and 2. For the final design, it was found that the result of this calculation was well under at $4.6 \mathrm{~mm}$ deflection. The dead and live load lateral deflection (i.e. at right angles to the load direction) must be less than $1 / 600$ of the span $(<0.17 \%)$. For the final design, it was found that the result was $3.8 \mathrm{~mm}$ which again was much less than allowable.

\section{Design to AS3990 - mechanical equipment - steelwork}

This standard is applicable in the design, fabrication, erection, repair, and alteration of steelwork concerning boilers, pressure vessels, lifts, cranes, mining equipment, gas and liquid petroleum piping systems, bulk handling equipment, etc., and uses the working stress design method. Australian 


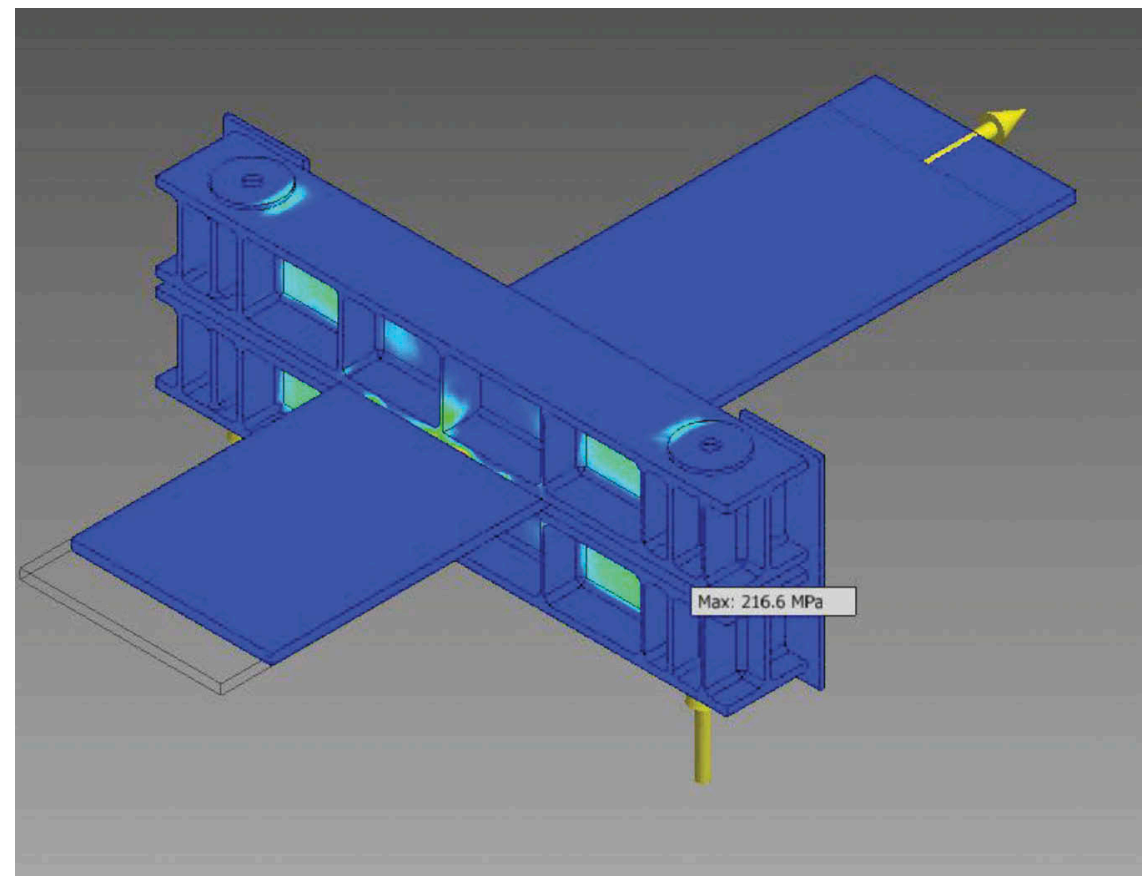

Figure 13. Clamp maximum stress.

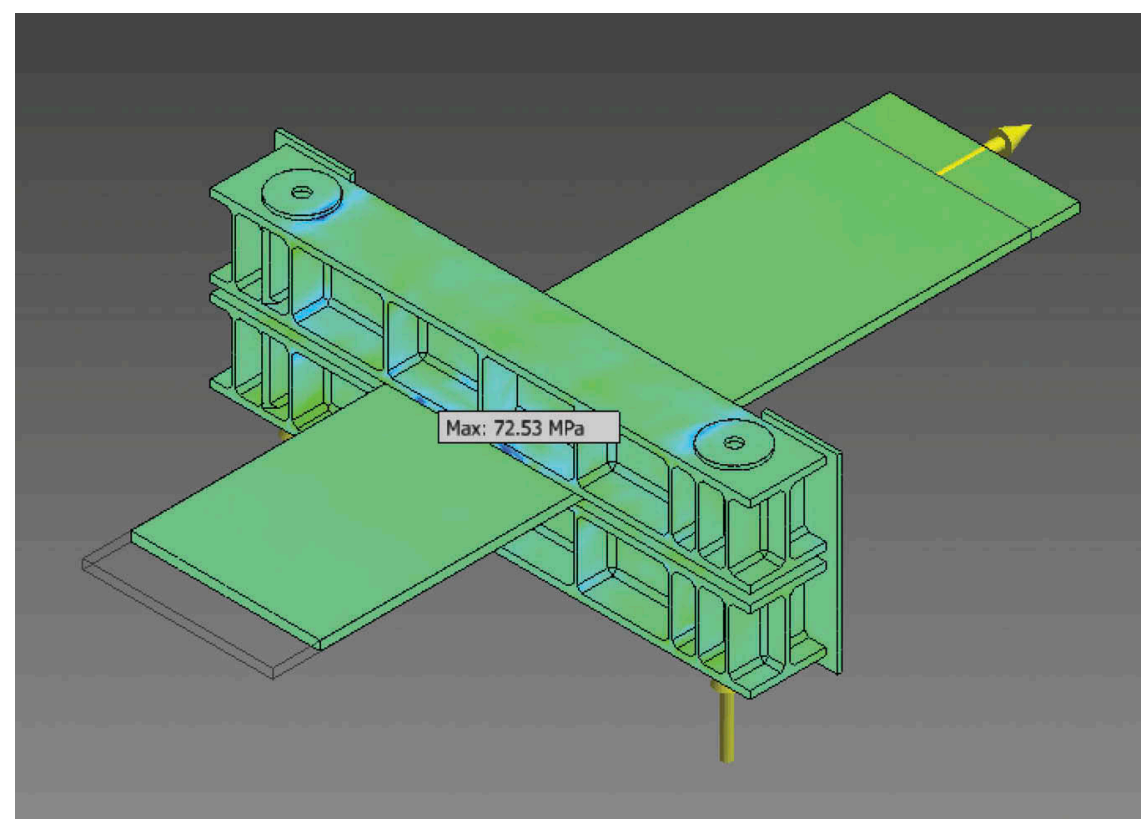

Figure 14. Maximum ZZ stress with NO Safety factors.

Standard 4100 is also a commonly used standard. The two standards essentially compare the limit state design method and the permissible stress design method. A comparison of case studies of mining equipment concluded that although the theoretical comparisons showed potentially large differences in individual members, there was little practical difference in the overall machine design (https://asec2016.org.au/ wp-content/uploads/2016/12/Simon-Edgar.pdf).

In order to design to comply with Australian Standard AS3990 - Mechanical Equipment - Steelwork a number of parameters need to be known in order to make all the necessary computations. The Standard should be referenced for most of the relevant equations as only the results of the calculations are reported here. The standard is quite broad so different design applications will activate different relevant sections of the standard.

The ultimate tensile strength of the material used in the construction of the clamp is $480 \mathrm{MPa}$. The yield strength is $360 \mathrm{MPa}$. Young's modulus is $200 \mathrm{GPa}$.

A standard 400WC328 cross-section will be used for the construction. The width of the section is $400 \mathrm{~mm}$ and the depth is $430 \mathrm{~mm}$. The flange thickness is $40 \mathrm{~mm}$ while the web thickness is $28 \mathrm{~mm}$. The gross cross-section is $41,800 \mathrm{~mm}^{2}$. The cross-section of the web is $12,040 \mathrm{~mm}^{2}$ while the flange crosssection is $16,000 \mathrm{~mm}^{2}$. The clear distance between the flanges is $350 \mathrm{~mm}$. The lesser/greater distance from the section neutral axis is $215 \mathrm{~mm}$. The distance from the outstand of the flange beyond the line of connection to a web is $186 \mathrm{~mm}$. The 


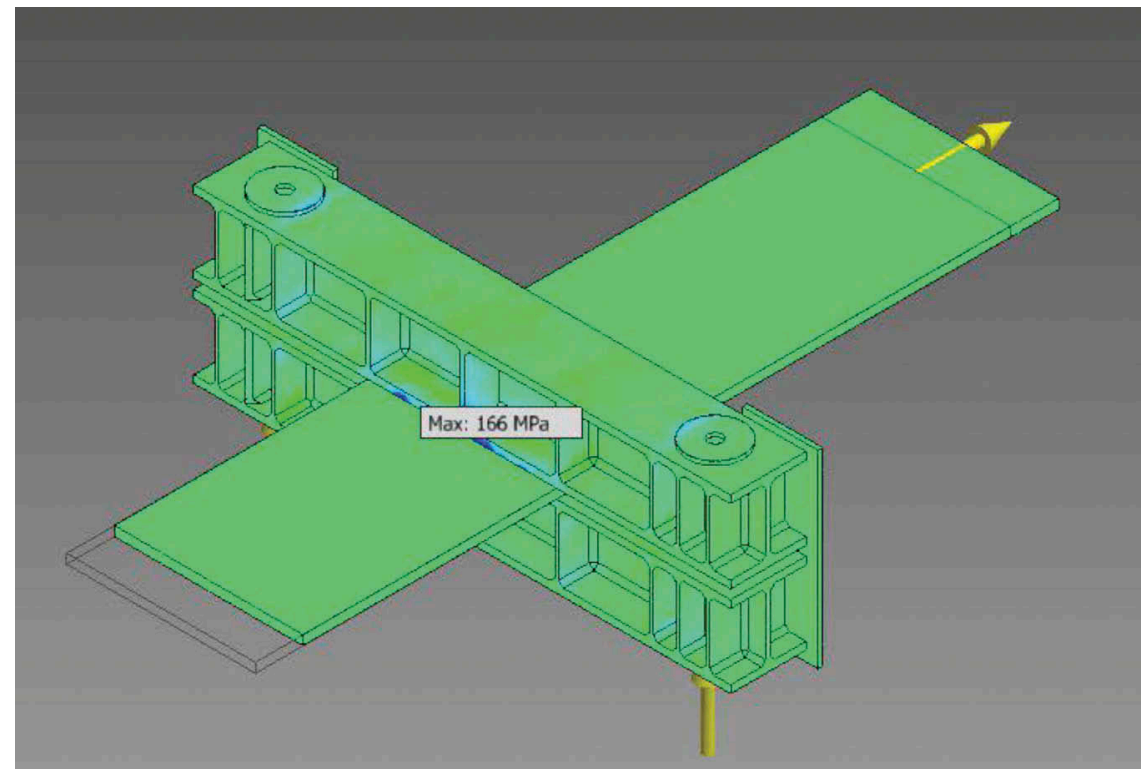

Figure 15. Clamp maximum YY stress with NO Safety factors.

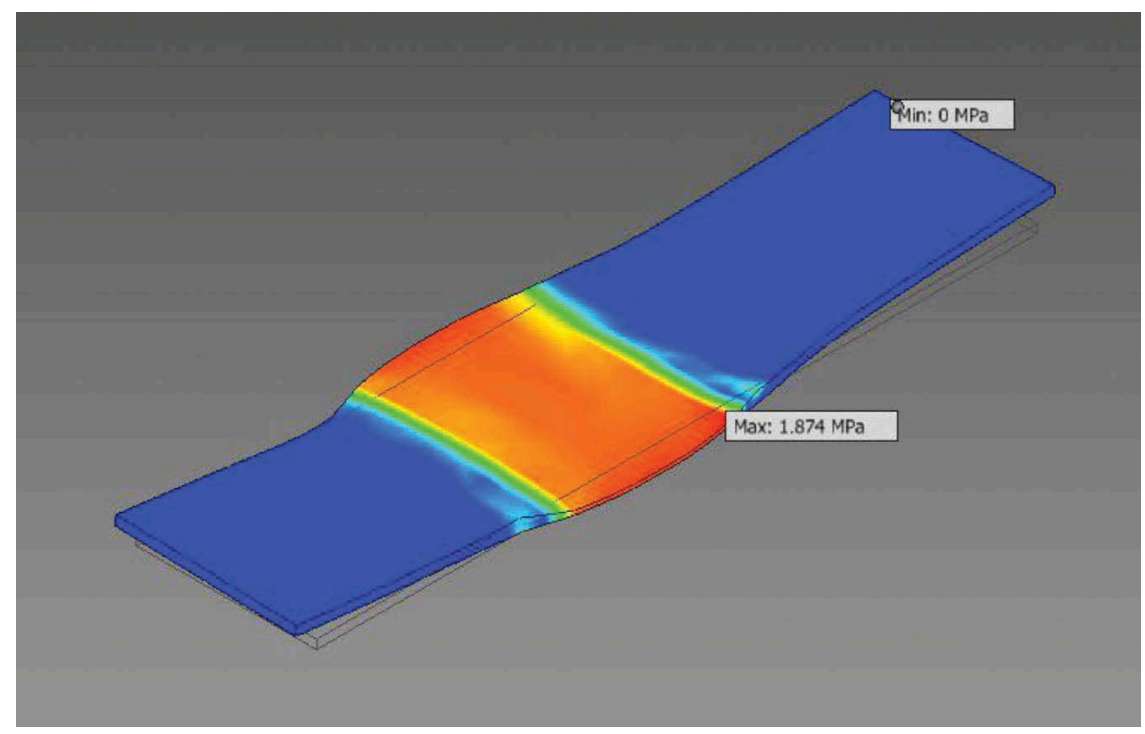

Figure 16. Stress in belt.

unsupported width of the flange between two adjacent faces of support is $188.5 \mathrm{~mm}$.

The second moment of inertia about the $x$-axis is $1,320 \times 10^{6} \mathrm{~mm}^{4}$ and about the $y$-axis is $427 \times 10^{6} \mathrm{~mm}^{4}$. The radius of gyration about the $x$-axis is $178 \mathrm{~mm}$ and about the $y$-axis is $101 \mathrm{~mm}$.

The length of the beam is $2,200 \mathrm{~mm}$. The slenderness ratio is 21.78. In this design case section 5.4 of the code does not apply.

The maximum permissible stress as per the standard clause 5.2 is 0.66 of the yield stress of the material as an "I" type beam is to be used. This, therefore, equates to $238 \mathrm{MPa}$. The maximum permissible compressive stress must be the greater of the general amount $(216 \mathrm{MPa})$, the amount for all beams (244 MPa), for other flanges or plates (254 MPa) or the permissible compressive stress for bending (238 MPa).

The maximum permissible stress in the beam when bent about the axis of maximum strength is thusly calculated as $162 \mathrm{MPa}$, noting that the elastic buckling stress of the beam is $8,924 \mathrm{MPa}$.
The elastic buckling stress of the beam is calculated with the following variables. The coefficient $K$ in this case is equal to 1 . The coefficient $K 2$ is equal to 0.5 . Thusly the variable $B$ equals 5,585.3 and variable $A$ equals 6,131.8. As a result, the elastic buckling stress of the beam is $8,924 \mathrm{MPa}$.

The maximum permissible shear stress is set at 0.45 times the yield strength so equals $162 \mathrm{MPa}$.

The average shear stress for an unstiffened web must be less than $133 \mathrm{MPa}$ or $1.27 \mathrm{E}-9$ and thus the permissible average shear stress must not exceed $133 \mathrm{MPa}$.

In this case, the axial stresses in uncased struts are calculated and the struts are deemed to be loaded concentrically. The variable $h$ is therefore equal to 0.014 . As such the elastic buckling strength of the strut in the $x$-axis is equal to 12,922 $\mathrm{MPa}$ while in the $y$-axis it is equal to $4,160 \mathrm{MPa}$. The Euler critical stress is calculated to be $4,160 \mathrm{MPa}$. Therefore, the permissible average compressive strength is $212.7 \mathrm{MPa}$. The average compressive strength for slender leg struts is $180 \mathrm{MPa}$. 


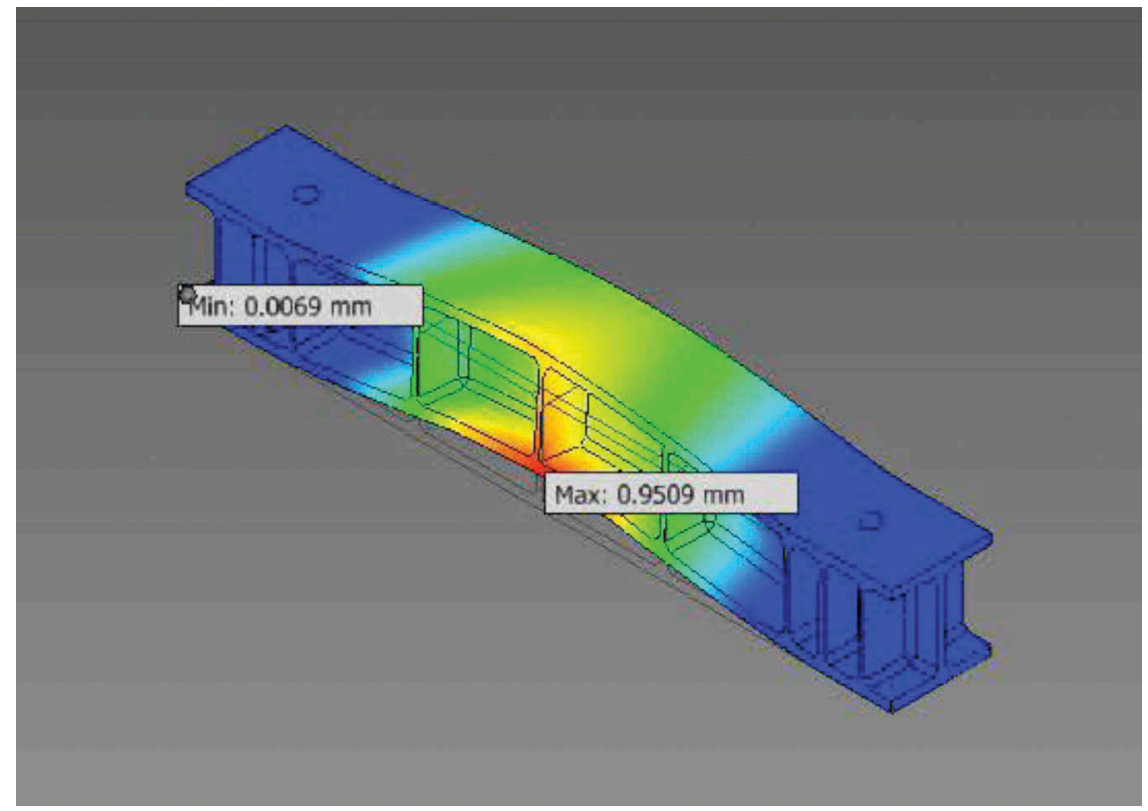

Figure 17. Top beam $Y$ deflection.

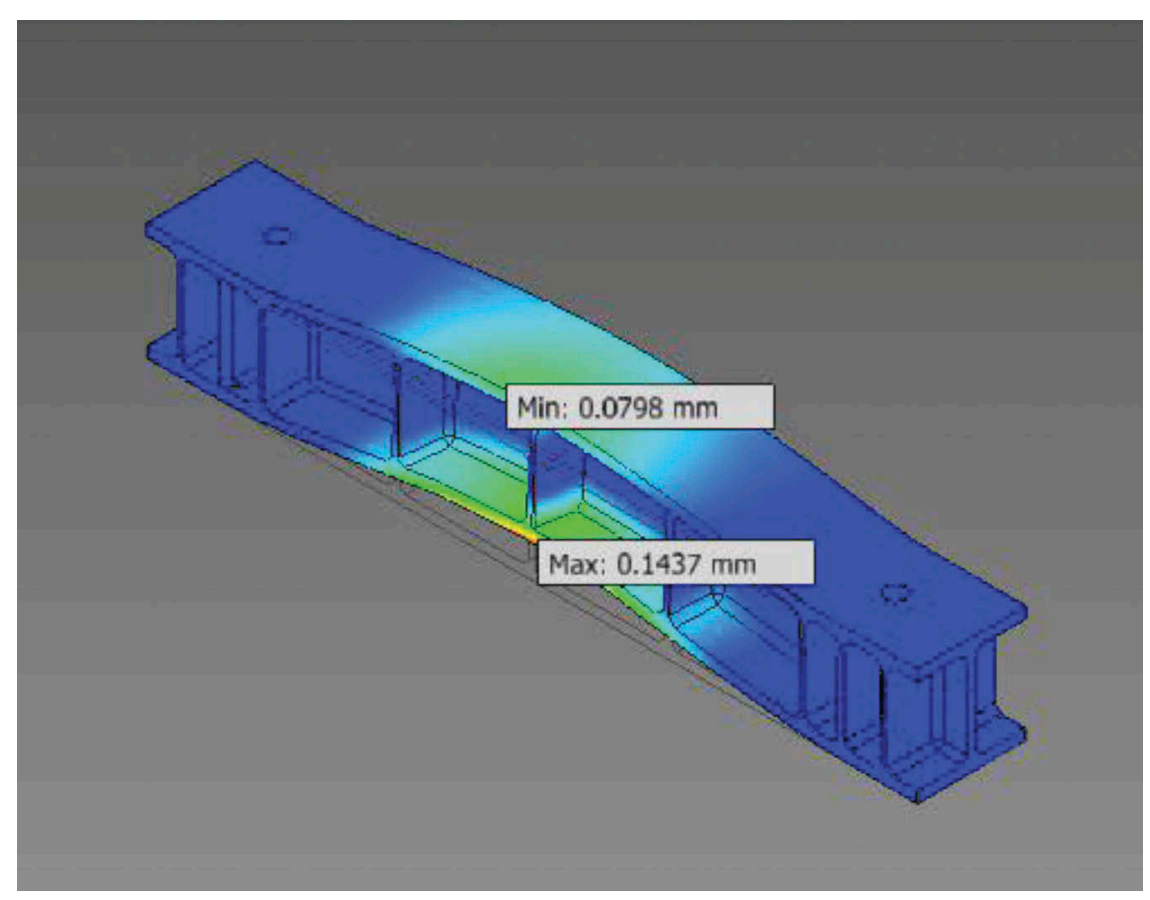

Figure 18. Top beam Z deflection.

For tension members, the axial tensile stress is set as a maximum to be 0.60 times the yield strength. As such, the permissible maximum axial tensile strength is $216 \mathrm{MPa}$.

A summary of permissible stresses is tabulated below in Table 1.

The total clamping force is calculated to be $900 \mathrm{kN}$. The friction coefficient between steel and rubber is set at 0.2 (Persson, 2020). The number of friction surfaces is two as the clamp operates on both sides of the belt. The braking force is therefore $360 \mathrm{kN}$. The length of the beam is $2,200 \mathrm{~mm}$. As such, the bending moment in the $\mathrm{x}$-axis is $4.95 \mathrm{E} 08 \mathrm{Nmm}$ and in the $y$-axis is 1.98E $8 \mathrm{Nmm}$.

The calculated compressive bending stress in the $x$-axis is therefore $80.6 \mathrm{MPa}$ while in the $y$-axis is 99.7 MPa. The percentage of the maximum allowable is therefore $33.9 \%$ in the $x$-axis and $42 \%$ in the $y$-axis. The sum is therefore $75.9 \%$ and hence the design complies with AS3990.

\section{Temperature rise}

The following calculation relates to the temperature rise of the clamps during an emergency braking scenario. A worstcase application on a large slope conveyor system is used for the calculation. For the conveyor system for which the clamps are being designed, the carry side belt length is $3,370 \mathrm{~m}$. The belt weight is $165 \mathrm{~kg} / \mathrm{m}$. The belt speed during operation will be $5 \mathrm{~m} / \mathrm{s}$. The slope of the conveyor incline is 15 degrees. The system is deemed to require 4 clamping stations. The belt 


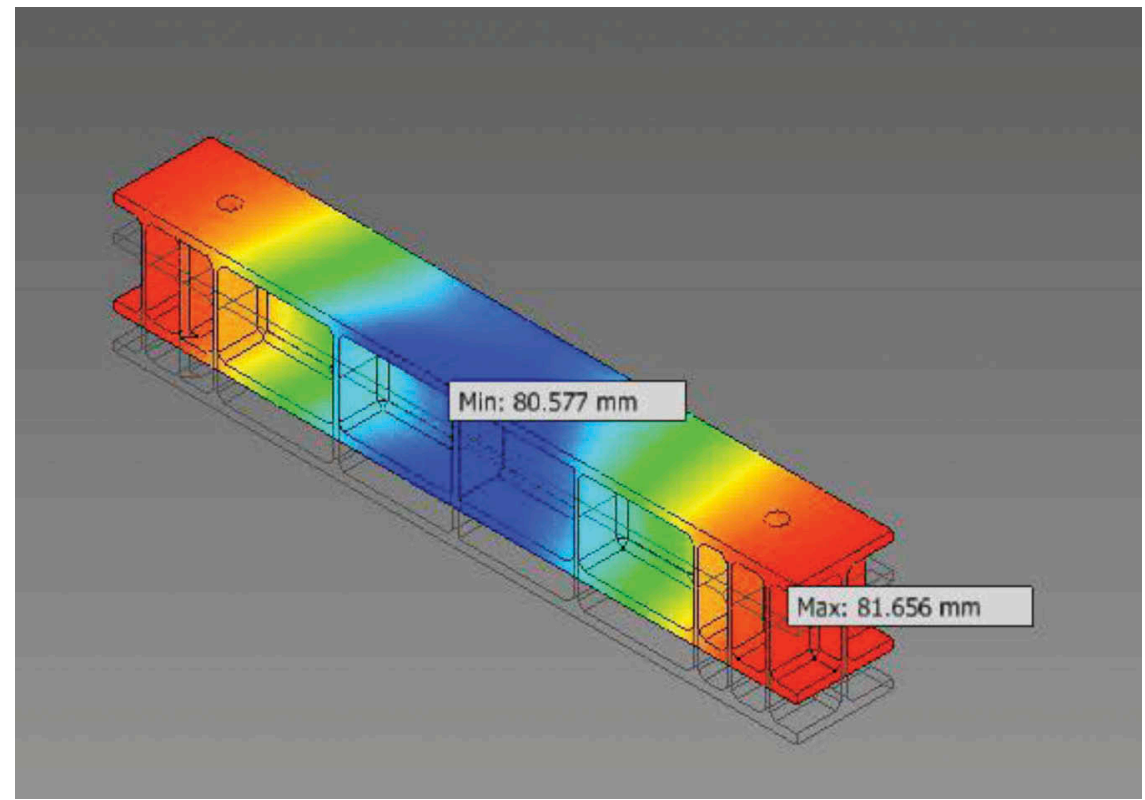

Figure 19. Bottom beam $Y$ deflection.

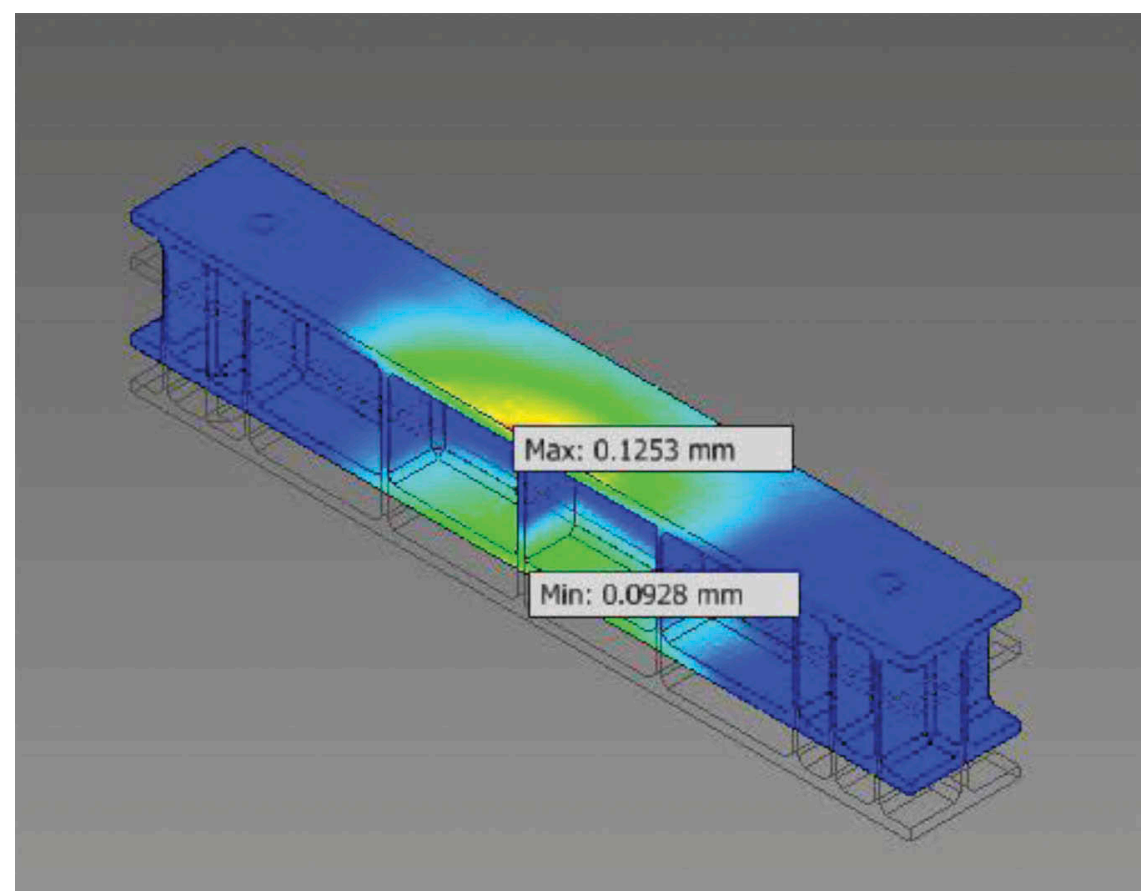

Figure 20. Bottom beam $\mathrm{X}$ deflection.

width is $1.8 \mathrm{~m}$. The clamp length is $0.4 \mathrm{~m}$. The dynamic factor is set at 1.5. The distance of the clamp on either side of the belt which is not in contact is therefore $0.3865 \mathrm{~m}$.

The kinetic energy of the belt while operating is 6,950,625 J and the potential energy is $5,442,769 \mathrm{~J}$. The sum of this energy is what will be required for the braking system to bring the belt to a stop. This sum is $12,393,394 \mathrm{~J}$. The time to bring the belt to a stop is deemed to be $10 \mathrm{~s}$. This power is therefore $1,239,339 \mathrm{~W}$. The heat flux is therefore 430,326 W/m (Australian Standard AS1418.1 - Cranes, Hoists and Winches General). As such the single stop temperature rise at each clamp is therefore $56^{\circ} \mathrm{C}$ plus ambient temperature for each clamp.

The clamps are seen to rise by $56^{\circ} \mathrm{C}$ which will not harm the belt. The conveyor belt is designed to handle a temperature of $56^{\circ} \mathrm{C}$ as it is designed for use in remote Australian mines where surface temperature of the belt can easily exceed this level.

\section{Finite element analyses}

Autodesk Inventor Professional 2014 was used to analyze the Dynamic Belt Clamp. The Dynamic Belt Clamp model was then constructed and used to produce the construction drawings.

The meshing used in the analysis was the default mesh specified by Inventor. This was used mainly to reduce computational time in the analysis. In addition to the default mesh, face sizings were included to increase the accuracy of the result. A face sizing of $1 \mathrm{~mm}$ was included at the surfaces of the axis of rotation. By introducing this mesh refinement, a structural error in the analysis of $0.64 \mathrm{MJ}$ was found. This is relatively small and not near the areas of maximum stress, at which, error of approximately zero is observed. This negligible error verifies the mesh as accurate giving confidence in the results. 
The Dynamic Belt Clamp was designed to be constructed from AS3679.2-400 grade material. This material has a yield stress of $360 \mathrm{MPa}$ and a Tensile strength of $480 \mathrm{MPa}$. The Dynamic Belt Clamp was restrained from the cylinders on the top beam as per the following figure. The top and bottom beams were also supported by a sliding surface as per the Figure 1. The steel cord conveyor belt has a Young's modulus of $190 \mathrm{GPa}$.

The load on the belt was applied as per the Figures 2 and 3. The loads on the clamp were applied as per the Figure 4.

A safety factor of 1.5 was used on the compressive load for a total of 130.5 Tonnes force $(1,280 \mathrm{kN})$. A safety factor of 2 was used for the lateral pull of the belt for a total of $40 \mathrm{~T}$ $(392.3 \mathrm{kN})$. The Dynamic belt clamp will be rated for a braking force of $20 \mathrm{~T}(196 \mathrm{kN})$. There are separate results below for the cases when no safety factor is used (i.e. actual loading). The convergence settings for von Mises stress were 5 maximum number of $\mathrm{h}$ refinements, a $5 \%$ stop criterion and $0.750 \mathrm{~h}$ refinement threshold.

\section{2,000 mm wide belt}

The following images relate to the condition where a $2,000 \mathrm{~mm}$ wide belt is being braked. As can be seen, the maximum stress is located at the inner most rib, closest to the belt on the top clamp as per Figure 5 .

The maximum stress in the clamp when braking the 2,000 $\mathrm{mm}$ wide belt is $210.6 \mathrm{MPa}$.

The maximum $\mathrm{ZZ}$ stress is located in the centre of the top beam, closest to the belt and measures $76.04 \mathrm{MPa}$ as per Figure 6.

The maximum YY stress is located at the end of the top clamp and measures $43.5 \mathrm{MPa}$ as per Figure 7.

The maximum stress on the $2,000 \mathrm{~mm}$ wide belt is 0.7646 MPa as per Figure 8.

The top beam deflects mostly at the ends of the beam and deflects by $0.829 \mathrm{~mm}$ as per Figure 9 .

The top beam deflects in the $Z$ direction in the centre of the beam and deflects by $0.6733 \mathrm{~mm}$ as per Figure 10 .

The bottom beam deflects in the $Y$ direction mostly in the centre of the beam and deflects by $0.02817 \mathrm{~mm}$ as per Figure 11.

The bottom beam deflects in the $Z$ direction mostly in the centre of the beam and deflects by $0.02258 \mathrm{~mm}$ as per Figure 12.

\section{$1,000 \mathrm{~mm}$ wide belt}

The following images relate to the condition where a $1,000 \mathrm{~mm}$ wide belt is being braked.

When the 1,000 mm wide belt is braked, the maximum stress is located at the end of the top beam and measures 216.6 MPa as per Figure 13.

The maximum $\mathrm{ZZ}$ stress is in the center of the top beam and measures $72.53 \mathrm{MPa}$ as per Figure 14 .

The maximum $\mathrm{YY}$ stress is also located in the centre of the top beam, closest to the belt and measures $166 \mathrm{MPa}$ as per Figure 15

The maximum stress on the belt is $1.874 \mathrm{MPa}$ as per Figure 16.

The top beam deflects in the $Y$ direction in the centre by $0.944 \mathrm{~mm}$ as per Figure 17.
The top beam deflects in the $Z$ direction in the centre of the beam by $0.0639 \mathrm{~mm}$ as per Figure 18 .

The bottom beam deflects in the $Y$ direction at the ends by $1.079 \mathrm{~mm}$ as per Figure 19.

The bottom beam deflects in the $\mathrm{X}$ direction in the centre of the beam by $0.0325 \mathrm{~mm}$ as per Figure 20 .

\section{Conclusions}

This paper addresses a case study of the design of a hydraulically controlled braking clamp for an incline conveyor to Australian Standards. The methodology acts as a guide for this process to be repeated in other applications. The results of the analysis are summarized as follows. AS3990 allows a maximum von Mises stress of $238 \mathrm{MPa}$. The FEA results for the $2,000 \mathrm{~mm}$ wide belt was $210.6 \mathrm{MPa}$ and for the $1,000 \mathrm{~mm}$ belt was $216.6 \mathrm{MPa}$. The design therefore passes this consideration. AS390 allows a maximum stress in the $X X$ and $Y Y$ direction when summed of being less than $238 \mathrm{MPa}$. Hand calculations return a result of $180.3 \mathrm{MPa}$. FEA results for the $2,000 \mathrm{~mm}$ wide belt return a result of $119.54 \mathrm{MPa}$ while the $1,000 \mathrm{~mm}$ wide belt has a result of $238 \mathrm{MPa}$. The design therefore passes this consideration. The maximum stress on the belt should not exceed 2.8 MPa as per the manufacturer's recommendation. FEA results for the $2,000 \mathrm{~mm}$ wide belt was $0.76 \mathrm{MPa}$ while for the $1,000 \mathrm{~mm}$ belt was $1.87 \mathrm{MPa}$. The design therefore passes this consideration. According to AS1418.1, the maximum vertical displacement shall be less than $4.4 \mathrm{~mm}$. This was found by FEA for the top beam to be $0.67 \mathrm{~mm}$ for the $2,000 \mathrm{~mm}$ wide belt and $0.94 \mathrm{~mm}$ for the $1,000 \mathrm{~mm}$ wide belt. This was found by FEA to be $0.83 \mathrm{~mm}$ for the bottom beam and the $2,000 \mathrm{~mm}$ wide belt and $1.08 \mathrm{~mm}$ for the $1,000 \mathrm{~mm}$ wide belt. The design therefore passes this consideration. Finally, AS1418.1 stipulates that the maximum longitudinal displacement shall be less than $3.7 \mathrm{~mm}$. FEA results for the top beam for the $2,000 \mathrm{~mm}$ wide belt was found to be $0.03 \mathrm{~mm}$ and $0.06 \mathrm{~mm}$ for the $1,000 \mathrm{~mm}$ wide belt. FEA results for the bottom beam for the $2,000 \mathrm{~mm}$ wide belt was found to be $0.01 \mathrm{~mm}$ and $0.04 \mathrm{~mm}$ for the $1,000 \mathrm{~mm}$ wide belt. The design meets the requirements of the standards for the proposed clamping loads and belt tensions. The combined stresses do not exceed allowable stress or displacement recommendations.

\section{Disclosure statement}

No potential conflict of interest was reported by the author(s).

\section{References}

Blazej, R., \& Jurdziak, L. (2017). Condition-based conveyor belt replacement strategy in lignite mines with random belt deterioration. IOP Conference Series: Earth and Environmental Sciences, 95(4), 1-11.

Daniyan, I. A., Adeodu, A. O., \& Dada, O. M. (2014). Design of a material handling equipment: Belt conveyor system for crushed limestone using 3 roll idlers. Journal of Advancement in Engineering and Technology, 1(1), 1. https://www.researchgate.net/publication/ 310462343_Design_of_a_Material_Handling_Equipment_Belt_ Conveyor_System_for_Crushed_Limestone_Using_3_roll_Idlers

Malek, F. I., Muaz, M., Rubiah, S., Mansor, M. N., \& Muda, M. A. (2015). Design and development to improve mechanism of conveyor system part 1. In 2nd Integrated Design Project Conference (IDPC) 2015 (pp. 1-12). Faculty of Mechanical Engineering, Universiti Malaysia Pahang.

Persson, B. N. J. (2020). Conveyor belt drive physics. Tribology Letters, 68 (1), 17. https://doi.org/10.1007/s11249-019-1256-6 
PMBROD367B. (2012). Remove and replace conveyor belts. Australian Government, Department of Education, Employment and Workplace Relations.

Popov, A. D. (2019). The composition theory in design and the industrial equipment design. IOP Conference Series: Materials Science and
Engineering, 698(3), 033001. https://doi.org/10.1088/1757-899X/698/ 3/033001

Wheatley, G. (2018). Design of a 10T Flake Pile Roller Stand. Industrial Engineering \& Management, 7(4), 4. https://doi.org/10.4172/2169-0316. 1000275 